\title{
A UNIVERSIDADE E A FAVELA: HIERARQUIA SOCIAL E GUERRA DE MEMÓRIAS
}

\author{
Mariana Machado Rocha \\ Universidade de São Paulo (USP), São Paulo, SP, Brasil
}

\begin{abstract}
Resumo: 0 presente artigo tem por objetivo apresentar elementos que caracterizam o olhar lançado por parte dos frequentadores da Cidade Universitária da Universidade de São Paulo (USP) para crianças e adolescentes moradores da Favela São Remo, vizinha ao campus universitário, a fim de compreender o modo como a hierarquia social, que perpassa a constituição de ambos os grupos, interfere na produção das memórias sobre a própria interação ocorrida entre eles. A análise foi elaborada a partir do caso da morte de Daniel Pereira de Araújo, adolescente de 15 anos, morador da Favela São Remo, que desapareceu quando brincava no campus da universidade, em novembro de 1997.
\end{abstract}

Palavras-chave: Universidade de São Paulo. Favela. Memória Histórica. Conflitos Sociais.

\section{INTRODUÇÃO}

Crianças e adolescentes moradores da Favela São Remo, vizinha à Cidade Universitária Armando de Salles Oliveira, campus Butantã da Universidade de São Paulo (USP), frequentavam o campusna década de 1990. Naquele período, Adorno afirmou:

[...] a simples presença dessas crianças e adolescentes, em resoluto contraste com 0 espaço "neutro", "higienizado" e "civilizado" que caracteriza esta comunidade, vem suscitando situações de tensão social bem como recrudescendo vez ou outra oportunidades para confronto, nas quais não está mesmo excluído o recurso à violência. (ADORNO, 1998, p. 1).

Nesse contexto ocorreu o desaparecimento de Daniel Pereira de Araújo, que foi visto pela última vez nadando com um grupo de amigos na Raia Olímpica da USP. Os bombeiros realizaram buscas sem sucesso e 3 dias depois seu corpo foi encontrado por membros da Guarda Universitária (ROCHA, 2016). De acordo com o resultado da perícia, a morte do adolescente deu-se por conta de afogamento. No entanto, há controvérsias a respeito das 
causas que o levaram a óbito e o caso foi entendido pelos moradores da São Remo como um assassinato. 0 presente texto apresenta os diferentes pontos de vista ${ }^{1}$ sobre 0 falecimento de Daniel com o intuito de pensar a influência das desigualdades sociais na disputa em torno das memórias.

\section{MENINOS NEGROS E POBRES NO CAMPUS}

Na década de 1990 saltou aos olhos dos frequentadores do campus a presença de crianças e adolescentes. Alguns grupos de alunos, docentes e funcionários da USP viaos como "bandos numerosos" de crianças "abandonadas" que moravam no campus. Dizia-se que eles eram cerca de 200 garotos, todos "drogados", que ameaçavam a segurança da "Comunidade USP". No entanto, o diagnóstico realizado por educadores do Programa Avizinhar (1998-2001) revelou que eram somente 64 crianças e adolescentes, todos meninos, alguns com idade entre 9 e 14 anos e uma menor quantidade com idade entre 15 e 18 anos. Nenhum deles usava drogas, todos moravam com suas famílias, a maioria estava matriculada em escolas de ensino regular e, em geral, iam ao campus para realizar trabalhos informais, como vender doces, catar latinhas ou cuidar de carros. Além de utilizar o campus como um espaço de lazer onde brincavam de bola, empinavam pipa, andavam de bicicleta, apanhavam frutas e, também, aprontavam travessuras. Alguns deles, eventualmente, cometiam pequenos furtos (ROCHA, 2016).

A diferença entre o imaginário construído sobre os garotos e o que o relatório do programa constatou evidencia um olhar negativo e assustado em relação ao perfil e à presença dessas crianças e adolescentes. Era comum dizer que os meninos desafiavam a Guarda, esse "desafiar" referia-se a ações como correr e fazer barulho próximo à biblioteca, entrar em locais proibidos ou perigosos e outras ações semelhantes, que, nesse contexto, eram encaradas como atos de vandalismo e marginalidade (ROCHA, 2016).

Trechos da Carta da Associação Atlética Acadêmica Politécnica ao Diretor da Escola Politécnica da USP (2000), reclamando da presença dos meninos, ilustram essa situação:

Eles passaram a abusar de nosso patrimônio, seja pisando e pulando em nossos sofás, seja depredando nossa mesa de sinuca, etc. A segurança do prédio nada podia fazer, pois os moleques simplesmente não os respeitam. Os seguranças sabem disso, pois alegam que, para pôr ordem na situação, necessitariam dar-lhes boas bordoadas, 0 que lhes acarretaria enormes problemas. [...] A questão é muito complicada, pois entendemos que a situação da segurança é delicada: os marginais se sentem "intocáveis", pois os seguranças não podem encostar neles, e esta é a única linguagem que entendem.

Apesar de não relatar nenhum tipo de violência praticada pelos meninos, os 
ROCHA, M. M.

remetentes da carta referem-se aos mesmos como marginais e afirmam acreditar que a violência física seria a única linguagem compreendida por eles. A brincadeira de pular em sofás possivelmente seria interpretada de outra forma se não fosse realizada por crianças pertencentes a um grupo social ao qual se atribuía os já mencionados predicados negativos (ROCHA, 2016).

No mesmo período havia alguns casos isolados de furto e violência praticados por alguns meninos, também moradores da São Remo. Com base no Ofício ao Diretor da Faculdade de Ciências Farmacêuticas da USP (1998), dentre os atos ditos violentos, há como exemplo uma ocorrência em que se afirma que eles jogavam copos de suco nas pessoas que passavam pelo corredor de um dos restaurantes universitários, ou até mesmo o caso em que um funcionário chamou a Guarda dizendo que os meninos estavam "munidos" de laranjas, lançando as frutas nas pessoas. O termo "munidos" remete a uma situação bélica, mas o ato de jogar laranjas em passantes aleatórios alude à ideia de uma travessura. Esse paradoxo presente na interpretação das ações das crianças no campus foi colocado por Bruna (2015 apud ROCHA, 2016), educadora do Programa Avizinhar. A partir de seu contato com as crianças e com os autores desse tipo de reclamação, para ela o que os meninos faziam no campus eram, em grande parte, "molecagens que viravam casos de polícia".

Assim, os membros da Associação Atlética da Escola Politécnica pediam punição para as crianças que pulavam em seus sofás e se mostravam indignados pelo fato de a Guarda Universitária não poder fazer uso de violência para deter os meninos. Essa situação mostra que a reação e o medo da comunidade USP diante da presença dos garotos eram, muitas vezes, exagerados, sendo que palavras como "marginais", "vagabundos", dentre outras semelhantes, eram costumeiramente utilizadas para fazer referência a eles.

Tendo em vista que os meninos que circulavam pelo campus eram majoritariamente negros, como aponta o Programa Avizinhar (1998-2001), esse tipo de abordagem diante de tais comportamentos nos remete ao trabalho de Carvalho e Rezende (2012), que num estudo sobre relações raciais na escola constata que há diferenças entre os critérios que professoras e professores utilizam para avaliar o comportamento de meninos e meninas. Para os meninos há um critério um pouco mais frouxo, pois considera-se alguma dose de insubordinação como parte integrante da masculinidade. No entanto, o mesmo não vale no caso de meninos negros, de quem se espera uma dose maior de submissão e agrado para que sejam considerados bons alunos. Qualquer atitude menos dócil e mais agressiva pode ser interpretada como um sinal de transgressão social, precursora de uma masculinidade violenta e amedrontadora. É possível pensar que a reação da comunidade USP em relação à presença dessas crianças tenha funcionado a partir da mesma lógica, gerando reações exageradas.

Barbosa-Pereira (2016) analisa os eventos que ficaram conhecidos como "rolezinhos", encontros de jovens moradores de bairros pobres, em sua maior parte negros e homens, em shoppings da cidade de São Paulo para a prática de lazer. Quando, em grupos grandes, brincando e fazendo barulho, eles começaram a cantar músicas de funk, os demais frequentadores dos shoppingse alguns lojistas se sentiram ameaçados e chamaram a polícia, que reprimiu os jovens violentamente, causando grande confusão. Apesar de não terem sido registrados furtos nem roubos, o rolezinho foi noticiado pela 
grande mídia como um arrastão. Barbosa-Pereira (2016) sustenta que o discurso do medo, disseminado pela grande mídia, estigmatizou os jovens como bandidos e foi utilizado para criminalizar seus encontros e justificar a violência policial contra eles.

0 autor lembra que os shoppings são espaços segregadores, que surgem justamente para resolver problemas urbanos como o medo da violência, controlando o acesso das pessoas (BARBOSA-PEREIRA, 2016). De acordo com ele, a perseguição policial aos rolezinhos se dava com base em características físicas, como o corte de cabelo e vestimentas dos jovens. Os jovens negros e homens eram os mais interpelados pela polícia mesmo sem terem feito nada de errado. Um grande aparato policial foi mobilizado para reprimi-los. Os jovens foram chamados pela mídia de bandidos, arruaceiros, delinquentes, vândalos, vagabundos e prostitutas. Expressões de racismo e preconceitos diversos foram manifestados.

Assim como os shoppings, a Cidade Universitária da USP é um espaço entendido como um local seguro, possivelmente por ser reservado à presença de pessoas pertencentes à classe média ou alta e a um grupo racial predominantemente branco, com altos níveis de escolaridade. Tal como nos rolezinhos, o perfil dos "invasores" do campus era composto por jovens do sexo masculino, utilizando roupas e cortes de cabelo típicos de jovens moradores de bairros pobres, e que circulavam pelo campus em grupos, principalmente com a finalidade de lazer, brincando, rindo e fazendo barulho. Se no episódio dos shoppings a violência policial foi justificada pelo medo, no campuso medo da comunidade universitária justificava as ações violentas por parte da Guarda Universitária da USP.

Barbosa-Pereira (2016) afirma que, nos shoppings, a ideia de segurança não englobava jovens pobres e negros se divertindo em grupos. Sua presença seria tolerada desde que consumindo de modo disciplinado ou na condição de subalterno. Algo parecido acontece com a população de moradores da São Remo. Quando presente no campus, ocupando cargos de trabalho socialmente desvalorizados ${ }^{3}$, essa população passa despercebida. Mas quando pretende utilizar esse local como um espaço de lazer, sua presença torna-se incômoda e é associada à violência e ao medo, ainda que infundados (ROCHA, 2016).

Naquele período, a fama e o olhar lançados sobre o grupo de meninos que de fato cometiam furtos e roubos ou possuíam comportamentos violentos, que eram minoria na totalidade de garotos que frequentavam o campus, acabavam recaindo sobre todos os outros, assim como os furtos e danos ao patrimônio causados por outras pessoas eram costumeiramente associados aos "moleques da favela", gerando uma permanente atmosfera de medo por parte de estudantes, docentes e funcionários da universidade, além de recorrentes conflitos entre as crianças e adolescentes que circulavam pela universidade e a Guarda Universitária. É em meio a esse contexto que ocorre a morte de Daniel Pereira de Araújo. 
ROCHA, M. M.

\section{O DESAPARECIMENTO E A MORTE DE DANIEL PEREIRA DEARAÚJ O: AS CONDIÇÕES DE PRODUÇÃO DOS RELATOS}

[...] tinha 10 moleques lá no dia, ele era o mais velho com 15 anos, [...] eles estavam nadando, [...] aí vieram os seguranças e tiraram eles da raia. Tiraram espancando mesmo, com pedaço de bambu, com vara. Bateram neles, todos os outros apanharam. Aí eles pularam a cerca e saíram, mas pularam tomando... apanhando. Então todos eles apanharam e o Daniel ninguém mais viu [...]. Aí foi aquela loucura, todo mundo procurando [...] até os bombeiros mergulharam e falaram: "não, na água ele não está". [...] Aí foi aquele corre em volta da raia, procurando, também nada, então na quarta-feira, de madrugada, a raia totalmente escura, né? [...] ligaram pra casa do pai dele e falaram que tinham achado o corpo dele na água (riso irônico). Então ficou uma coisa meio estranha, o pai dele também quando foi reconhecer o corpo, ele viu que tinha... Parecia que tinha levado uma pancada na testa... Essa parte [aponta para o meio da testa] tava meio funda assim, e ele ficou de domingo até quarta na água, né? Mas não estava em estado avançado de decomposição [...] (PEDRO apud ROCHA, 2016, p. 79-80).

No final da gestão anterior aconteceu uma tragédia, provocada em grande parte pelo descuido dos moradores da comunidade São Remo. Um jovem, nadando na raia olímpica (da USP), e vendo um guarda chegar, tentou esconder-se e acabou sugado pela areia quase movediça do fundo da raia, um lugar muito inapropriado para nadar (MARCOVITCH apud MOTOYAMA, 2006, p. 286). (...) A resposta dada [para a morte de Daniel] foi o Projeto Avizinhar, que começou a ser delineado ainda durante a minha gestão na Pró-Reitoria, mas implementado tão logo assumi o cargo de reitor. Uma resposta da área de extensão para tratar dessa comunidade a nossa volta mais como vizinha do que como comunidade exclusa (Ibid., p. 47).

No primeiro trecho, Pedro, parente próximo de Daniel, relata a morte do adolescente como um marco para as relações entre a USP e a São Remo, o início de uma "guerra". Na época em que aconteceu o caso, Pedro tinha aproximadamente 14 anos e durante a entrevista já contava com 30 anos de idade. Os efeitos do contexto da entrevista e do tempo decorrido entre os acontecimentos e o relato serão discutidos oportunamente.

O segundo trecho trata-se de uma fala de Jacques Marcovitch, que ocupava o cargo de Pró-Reitor de Cultura e Extensão no período em que ocorreu o falecimento de Daniel. Na época, Marcovitch pleiteava o cargo de reitor da USP, para o qual foi nomeado algumas semanas depois. 0 depoimento é parte de uma entrevista realizada em 2004, 7 anos após os acontecimentos, a propósito da publicação de um livro organizado por Shozo Motoyama - em comemoração aos 70 anos da Universidade de São Paulo.

A entrevista, concedida no contexto de celebração do aniversário da universidade, colocada ao lado de outras entrevistas com reitores e pessoas de destaque na história da Universidade de São Paulo, originou um livro cuja função é apreciar e congregar memórias dessa instituição. Ao ostentar suas realizações na área de cultura e extensão universitária, ele menciona a morte de Daniel como um terrível acidente, a partir 
do qual sua gestão propõe a criação do Programa Avizinhar.

A maneira como o ex-reitor se refere à tragédia destaca o descuido da comunidade São Remo em permitir que os jovens nadassem em um lugar inapropriado e menciona uma suposta tentativa de fuga do adolescente ao ver um guarda, o que teria causado então a sua morte por afogamento. Assim, a narrativa apresentada pelo ex-reitor evoca a imagem de "delinquentes" já existente sobre os meninos da São Remo, não menciona as suspeitas de envolvimento da Guarda e os conflitos originados a partir da morte de Daniel e destaca o programa de Extensão Universitária instituído em sua gestão após a tragédia. Pollak (1989) afirma que,

Toda organização política, por exemplo - sindicato, partido, etc, veicula seu próprio passado e a imagem que ela forjou para si mesma. Ela não pode mudar de direção e de imagem brutalmente a não ser sob risco de tensões difíceis de dominar, de cisões e mesmo de seu desaparecimento, se os aderentes não puderem mais se reconhecer na nova imagem, nas novas interpretações de seu passado individual e no de sua organização. 0 que está em jogo na memória é também o sentido da identidade individual e do grupo. (POLLAK, 1989, p. 10).

Assim, podemos pensar que a constituição da representação do lugar social da Universidade de São Paulo é algo cuidadosamente elaborado pelos atores sociais envolvidos nesse projeto, e a própria criação de um livro que celebra os 70 anos de existência da USP pode ser entendida como uma publicação em que se realiza 0 "enquadramento da memória" sugerido por Pollak (1989). A morte de um garoto pobre, morador de favela num dos campi da USP, sob suspeita de assassinato perpetrada pela Guarda Universitária, poderia causar uma mancha na história da universidade e gerar cisões entre seus aderentes. Esse é um risco real, como podemos ver no trecho a seguir:

A morte de Daniel Pereira de Araújo no câmpus da Universidade de São Paulo deixa um marco triste na história da instituição. Oficialmente, não se sabe o que se passou no domingo de 2 de novembro quando o garoto, de 15 anos, desapareceu. Os amigos do Daniel alegam ter sido espancados pelos seguranças do câmpus, que, por sua vez, negam a acusação. (...) Morre gente de favelas de formas mal explicadas todos os dias no Brasil, sei. Mas a morte de Daniel, seja por acidente, seja criminosa, denuncia a deterioração das relações entre uma das mais respeitadas instituições intelectuais do País e a pobreza ao seu redor. (...) o papel da universidade não é apenas oferecer ensino e desenvolver pesquisas. Cabe-Ihe também, promover a cidadania. Enquanto a USP for conhecida como um lugar onde a circulação de populares é proibida e garotos são espancados, cumprir tal função vai ser difícil. A Universidade de São Paulo, na qual tive a honra de estudar, lutou em prol da democracia durante décadas. A luta continua. (SHIRTS, 1997).

A crônica publicada no jornal 0 estado de S. Paulo e assinada por Shirts, que se apresenta como ex-aluno da USP, mostra uma pessoa envergonhada com a possibilidade 
de ter vinculada à sua formação a imagem de uma instituição em que "garotos são espancados". A menção de Shirts à luta em prol da democracia, como uma marca de orgulho na memória dessa universidade, mostra que esse caso poderia significar uma ruptura brusca com essa imagem.

A argumentação de Marcovitch ocorre em um livro, meio privilegiado por sua possibilidade de registro e divulgação, e ocorre em um momento posterior ao fervor dos acontecimentos. Ao defender a instituição, à qual esteve ligado durante boa parte de sua vida, Marcovitch defende a sua própria imagem e atua para a constituição da memória de um reitor cuja diferença em relação aos outros se deu pela própria criação do Projeto Avizinhar. Fica consagrada, assim, uma memória que destaca o compromisso social da USP e do próprio Marcovitch.

Michael Pollak (1989) afirma que, se por um lado os grupos dominantes detêm os meios que possibilitam disseminar e legitimar um determinad o ponto de vista sobre a história, por outro, os grupos subalternos, detentores de memórias reprimidas e silenciadas, perpetuam suas narrativas dissonantes da memória oficial de maneira informal, no quadro familiar e em redes de sociabilidade afetiva e/ou política. Nesse sentido, existe uma disputa em torno da memória, que ocorre de maneira silenciosa, até que um determinado contexto político e social situado no tempo favoreça a emergência de narrativas que permaneceram ocultas durante longos períodos, ou seja, "o presente colore o passado".

A partir dessa perspectiva, a memória apresentada pelos moradores entrevistados pode ser compreendida como uma memória subalterna que se perpetuou a despeito das narrativas "oficiais". O relato de Pedro descreve a cena em que teria ocorrido o espancamento dos meninos que estavam junto com Daniel no dia de seu desaparecimento: a quantidade de meninos, a idade de Daniel, os objetos utilizados pelos seguranças para bater nos meninos, a fuga deles apanhando da guarda, o desaparecimento de Daniel, a busca sem sucesso realizada pelos bombeiros, o aparecimento do corpo de Daniel na raia numa quarta-feira e, por fim, o aspecto do corpo do menino na ocasião são detalhes que sugerem a existência de uma memória viva e nítida, apesar de decorridos aproximadamente 15 anos após os acontecimentos. Uma memória minuciosa e emocionada em que se destaca a suspeita sobre o envolvimento da Guarda Universitária da USP na morte de Daniel.

Nos relatos dos jovens entrevistados, o fechamento do campus, ocorrido aproximadamente dois anos antes da morte de Daniel, teria dado início a uma série de conflitos com a Guarda da USP. Pedro, Murilo e Guilherme utilizaram o termo "guerra" para se referir a esses conflitos:

A guerra na verdade já existia antes, né? Porque fecharam a USP e a gente queria entrar, né? Nós éramos acostumados a ir lá todo fim de semana, às vezes até na semana mesmo, quando não tinha aula à tarde, nas férias, ia lá, soltar pipa, jogar bola, então, era um espaço que a gente frequentava, e de repente chegou alguém, colocou um muro lá e falou "não, vocês não podem mais entrar", então, chegava fim de semana a gente ia pra tentar entrar eles não deixavam, aí pra entrar a gente tinha que pular o muro... (PEDRO apud ROCHA, 2016, p. 158). 
O uso da palavra "guerra" indica a hostilidade e a violência presentes nas interações entre as crianças e adolescentes com a Guarda da USP. Guilherme acrescenta que, após a morte de Daniel, houve um acirramento desses conflitos e que um de seus desdobramentos foi a desativação da guarita situada em um dos acessos da USP para a São Remo. Nas palavras dele:

Teve a morte do Daniel. Eu fiquei sabendo que foram os seguranças que afogaram ele. Aí que foi a bagunça, né? Que foi... quebrar tudo dentro da USP mesmo, virou um campo de guerra mesmo. Eu lembro como se fosse hoje, né? (...) hoje mesmo (...) não tem segurança na guarita. É quebrada até hoje. E tem anos, né? Que aconteceu isso. Acho que por isso, hoje acho que eles devem ter medo de colocar segurança naquele portão. Aí foi o que aconteceu, né? 0 pessoal ficava jogando pedra pra dentro da USP, na hora que passava a viatura, passava carro, tocaram fogo em pneu, essas coisas assim. (GUILHERME apud ROCHA, 2016, p. 166).

A guarita mencionada por Guilherme, situada na portaria de pedestres que dá acesso da São Remo para a USP, na parte baixa, próxima ao Museu de Arqueologia e Etnologia, até 0 início de $2017^{4}$ era a única entre todas as portarias de pedestres da USP que se encontrava completamente destruída e na qual não havia seguranças responsáveis pelo controle da entrada nos horários estipulados pela Coordenadoria do Campus. A narrativa dos jovens entrevistados indica que a entrada da São Remo para o campus ficou livre após os protestos realizados na ocasião da morte de Daniel, que envolveram a queima da guarita.

Durante anos a estrutura física caracterizada pela destruição da guarita foi uma espécie de monumento, que demarcava a reação dos moradores à morte de Daniel e à proibição de entrada no campus. O termo "campo de guerra", utilizado por Alisson (2015 apud ROCHA, 2016), refere-se a uma manifestação realizada por moradores da São Remo, estudantes e funcionários da USP diante da suspeita de envolvimento da Guarda Universitária:
Um protesto contra a morte do estudante Daniel Pereira de Araújo, 15, encontrado morto anteontem na raia olímpica da USP (Universidade de São Paulo), terminou em depredação na tarde de ontem na Cidade Universitária (zona sudoeste de São Paulo). Duas cabines da segurança universitária foram incendiadas pelos manifestantes, que também arrancaram um portão, quebraram vidros de prédios, danificaram telefones públicos e coberturas de pontos de ônibus. (CABRAL, 1997d).

Quatro jovens foram entrevistados no início de 2015. Pedro, Murilo, Guilherme e Alisson tinham idade entre 9 e 17 anos na época em que ocorreu o falecimento de Daniel e não eram parte do grupo de meninos que esteve presente na Raia Olímpica da USP na ocasião do desaparecimento do adolescente. Apesar do intervalo de tempo entre os acontecimentos e as entrevistas, em suas narrativas não há dúvidas com relação ao envol 
ROCHA, M. M.

vimento da Guarda na morte do adolescente.

Pollak (1989) afirma que a metodologia baseada na memória oral ganhou espaço sobretudo nas situações em que há conflito e competição entre memórias concorrentes, ou seja, em situações em que a narrativa hegemônica silencia memórias subalternas que permanecem latentes e possibilita captar elementos que não se materializaram ou não foram registrados justamente devido à posição subalterna ou marginalizada dos grupos detentores dessas memórias. Assim, é possível pensar que o estigma ${ }^{5}$, que acompanhava os meninos que frequentavam o campuse a população moradora da São Remo como um todo, também incide sobre o potencial de disseminação e credibilidade de suas memórias nos meios hegemônicos de consagração. Ainda assim, tal memória se perpetuou de maneira informal no grupo dos moradores.

A faixa etária de Pedro, Murilo, Alisson e Guilherme na época dos acontecimentos era bastante próxima à do próprio Daniel. Assim como ele, durante a infância os entrevistados utilizavam o campus da USP como espaço de lazer. Os conflitos com a Guarda da USP, as travessuras na Cidade Universitária, as reações exageradas da Comunidade USP, bem como os olhares preconceituosos recebidos, configuraram parte importante da memória de suas infâncias. Portanto, há um conjunto de elementos que situa os entrevistados numa posição muito próxima à de Daniel. Esse elevado grau de identificação entre eles possivelmente atua sobre a maneira como eles interpretaram e rememoram os acontecimentos daquele período, afirmando a ocorrência do "assassinato" de Daniel, palavra utilizada por Murilo. a seguir:

É possível visualizar a grande comoção advinda dos acontecimentos nas notícias

A família do estudante Daniel Pereira de Araújo, 15, não acredita que ele tenha morrido afogado. Desde o início, a família culpou os seguranças da USP pelo desaparecimento. [...] "Não é possível que o corpo tenha sido encontrado de madrugada, em um lugar totalmente escuro e que já tinha sido vasculhado pelos bombeiros e pela polícia", afirmou a bancária Denilza Pereira de Araújo, 21, irmã de Daniel. [...] irmão mais velho de Daniel, afirma que o estudante sabia nadar "muito bem" e conhecia o local. "Duvido que ele tenha morrido afogado. Ele costumava nadar na raia desde criança." [...] Durante o depoimento dos seguranças, cerca de 200 pessoas protestaram na porta da delegacia. [...] Quando os seguranças chegaram, foram recebidos com os gritos de "assassinos". (CABRAL; OLIVEIRA, 1997).

Cerca de 300 pessoas participaram na tarde de ontem do enterro do estudante Daniel Pereira de Araújo (...) A maioria dos estudantes carregava cartazes feitos de cartolina protestando contra a morte (...). Na chegada do cortejo ao cemitério, Lizete falou à imprensa pela primeira vez desde a morte do filho. "Meu filho foi morto por seguranças da USP. Estou sofrendo desde domingo e só vou sossegar quando colocar esses assassinos atrás das grades. Se a USP não colocar, eu mesma vou fazer justiça. Não foi a raia olímpica que matou meu filho, ele sabia nadar. Foram os seguranças da USP", desabafou Lizete, pouco antes de desmaiar novamente. [...] Depois do enterro, J oão Batista [pai de Daniel] pediu a todos que rezassem um painosso. Após a oração, todos gritaram "justiça". (CABRAL, 1997e). 
A quantidade de pessoas presentes nesses episódios, os gritos por justiça e de "assassinos", indicam a força da repercussão da morte de Daniel naquele momento. A São Remo é uma favela de pequenas proporções territoriais, o que pode ter colaborado com a disseminação, entre os moradores, de um ponto de vista comum a respeito da morte de Daniel. É possível pensar que a força dessa comoção coletiva tenha colaborado para a perpetuação de uma memória tão nítida e distante da apresentada pelo ex-reitor da USP entre os entrevistados.

Toda a série de predicados negativos atribuídos aos meninos que frequentavam o campus, como "marginais", "crianças abandonadas", "bandos numerosos", "ameaça à segurança", que "só entendem a linguagem da violência", recaem sobre o próprio Daniel, os meninos que estavam junto a ele no momento de seu desaparecimento e também sobre o conjunto de rapazes entrevistados. 0 impacto dessa imagem negativa sobre a credibilidade da versão que esses atores apresentam sobre os acontecimentos deu-se desde o período em que a situação ocorreu, culminando também na produção de documentos sobre a questão, de forma que o trabalho de elaboração histórica so bre esses acontecimentos, efetuado a partir de um conjunto específico de fontes documentais, pode involuntariamente negligenciar a narrativa dos meninos que estavam com Daniel, tornando invisível a própria disputa em torno da memória desse acontecimento. Um bom exemplo dessa situação é o relatório produzido pela Comissão Independente criada pela USP para apurar os acontecimentos.

O Relatório da Comissão de Acompanhamento do Inquérito, instaurado no $93^{\circ}$ Distrito Policial para apurar as circunstâncias e eventuais responsabilidades envolvendo a morte de Daniel Pereira de Araújo, instituída por Portaria/253197/GR, de 7 de novembro de $1997^{6}$, apresenta informações sobre a morte de Daniel a partir de documentos e de entrevistas ${ }^{7}$. Entre as vozes registradas no documento temos a Associação dos Docentes da Universidade de São Paulo (Adusp), o Diretório Central dos Estudantes da USP (DCE) e o Sindicato dos Trabalhadores da Universidade de São Paulo (Sintusp). O registro mostra a multiplicidade de vozes no interior da Universidade de São Paulo, com destaque para a existência de grupos que não se alinhavam à depreciação ostensiva dos moradores e defesa incondicional da instituição. Ainda assim, ouvir os moradores não foi parte da estratégia dessa Comissão. Pollak (1989) afirma que a escolha das testemunhas autorizadas, feita pelos responsáveis pela produção dos enquadres de memória, é parte importante do trabalho de controle de memória na produção de um relato que propaga a imagem que uma associação tem de si mesma para seus membros e para a sociedade.

O contato com os depoimentos dos meninos na produção do relatório se dá apenas por meio do auto dos inquéritos, que é pouco explorado. A versão dos moradores, que questiona mesmo os resultados de exames com estatuto de verdade, como o laudo do Instituto Médico Legal (IML), não fica registrada, o que evidencia sua desvalorização também no interior dos grupos inclinad os a questionar a maneira como a USP se relaciona com a população moradora da favela vizinha. Mais uma vez, a hierarquia social definiu o status das testemunhas autorizadas, cujos pontos de vista seriam dotados de maior ou 
ROCHA, M. M.

menor poder de perpetuação, causando impactos na criação de uma narrativa histórica sobre a USP e suas relações com a favela vizinha.

0 registro realizado pela imprensa se diferencia dos demais nesse ponto. A abordagem dos jornais Folha de São Paulo e $O$ Estado de S. Paulo trazem as vozes dos diversos agentes envolvidos nesses acontecimentos, inclusive a dos moradores. Além disso, nesse caso as notícias foram elaboradas a partir de afirmações feitas no calor dos acontecimentos. Foram ouvidos os meninos que estavam junto com Daniel no dia de seu desaparecimento, que falaram sobre o quanto haviam apanhado naquele dia, narrativa que havia sido confirmada pelo exame de corpo delito (SCHIVARTCHE, 1997; ANTAR, 1997a). Foram ouvidos familiares de Daniel, que manifestaram sua tristeza, indignação e expectativas com relação à urgência de se fazer justiça (CABRAL; OLIVEIRA, 1997). Crianças e adolescentes moradores da São Remo relataram o medo de voltar a frequentar o campus depois do ocorrido e alguns narraram outros episódios de violência por parte da guarda universitária (OLIVEIRA, 1997).

Pessoas que participaram da manifestação também foram entrevistadas e disseram estar cansados de serem discriminadas e tratadas como bandidas pela USP e que suas reivindicações eram por justiça em relação à morte de Daniel e indenização para sua família (LEAL, 1997). Houve falas sobre o sentimento de exclusão dos moradores em relação à Universidade que, por outro lado, procurava por eles quando precisava realizar pesquisas (BASTOS, 1997).

A grande imprensa escutou também dirigentes da USP, como o então Reitor Flávio Fava de Moraes e Jacques Marcovitch, que reafirmaram a importância do fechamento do campus, argumentando que a universidade não tinha estrutura apropriada para receber a população aos finais de semana. Flávio disse também que nadar em local proibido havia sido uma imprudência dos garotos e que a guarda estava fazendo seu trabalho ao retirar os meninos da Raia Olímpica. Marcovitch anunciou a criação de um programa de formação profissional para jovens pobres moradores do entorno do campus e a criação de propostas de atividades culturais na Cidade Universitária (ROSSETI, 1997; CARELLI, 1997). Representantes da USP também afirmaram que a Guarda Universitária estava sendo hostilizada e que a posição da Universidade seria defendê-la enquanto nada fosse comprovado, justificaram a ado ção da entrada provisória da Polícia Militar no campus (CABRAL, 1997a; PIVETTA, 1997) e, por fim, afirmaram ${ }^{8}$ haver uma relação de abertura da USP em relação à favela São Remo.

Estudantes também foram ouvidos pelos jornais e ficou registrada a pluralidade de vozes nesse grupo. Alguns afirmavam compreender e apoiar a reação dos moradores diante da morte do garoto, enquanto que outros diziam defender a elitização e fechamento do campus, propondo a extinção dos cursos noturnos como forma de reduzir a violência na Cidade Universitária (PURVINNI, 1997; LEAL, 1997a). Além do registro dessa multiplicidade de vozes, o jornal Folha de São Paulo foi o veículo de publicação de cinco artigos de opinião (BORIN, 1997; FELINTO, 1997; KEHL, 1997; BORIN, 1997a; NETO, 1997), que desenvolvem um caloroso debate acerca da postura da Universidade ${ }^{9}$, as políticas de acesso a essa instituição e a relação desta com o entorno de um de seus campi ${ }^{10}$. Os temas levantados pelo conjunto de vozes corroboram a afirmação de Pollak (1989) de que o presente colore o passado. 


\section{CONSIDERAÇÕES FINAIS}

As fontes de naturezas distintas nos fornecem visões múltiplas sobre a mesma situação e cada uma delas se encontra marcada pelo seu contexto de produção. A ideia de confronto que surge na ampla utilização de termos bélicos pelos moradores e jornalistas para se referir às relações entre a Favela São Remo e à USP é útil para nos ajudar a perceber a extrapolação desse embate para o campo de produção das memórias, no qual cada grupo tem, a partir de sua posição no espaço social, condições e meios diferentes de perpetuar suas narrativas a respeito dos mesmos acontecimentos. Trata-se de uma verdadeira "guerra" pelos sentidos e significados da morte de Daniel e pela maneira como a memória e a história acerca desse acontecimento foram registradas e constituídas.

A hierarquia presente no mundo social fornece a alguns grupos e personagens, nesse caso o Reitor da USP, os meios de divulgação e a legitimidade que possibilitam a predominância de sua versão, que facilmente passa a ser compreendida como parte da história oficial. No entanto, isto não significa uma supressão total das memórias subalternas, que, apesar de reprimidas, seguem perpetuando com bastante vivacidade, possíveis de serem captadas a partir da escuta dos grupos subjugados, ainda que não entrem para o conjunto de memórias consagradas.

Artigo recebido em: 30/10/2018

Aprovado para publicação em: 19/12/2018

THE UNIVERSITY AND THE SLUM: SOCIAL HIERARCHY AND THE STRUGGLE FOR HISTORICAL MEMORY

ABSTRACT: This present paper concerns to present the image constructed by community from the University of São Paulo over the children and adolescents which live in São Remo Slum, one of the university neighbors, in order to understand how the social hierarchy which permeates the constitution of these particular groups interferes over the production of memories of the social interactions between them. The analysis was based on the case from the death of Daniel Pereira de Araújo, an adolescent aged 15 which lived in São Remo Slum, which disappeared while he was playing on the University of São Paulo's campus in November 1997.

KEYWORDS: University of São Paulo. Slum. Historical Memory. Social Conflicts. 


\section{LA UNIVERSIDAD Y LA FAVELA:J JRARQUÍA SOCIAL Y LA GUERRA DE LAS MEMORIAS}

RESUMEN: El presente artículo tiene por objetivo presentar elementos que caracterizan la mirada lanzada por parte de los asistentes de la Ciudad Universitaria de la Universidad de São Paulo (USP) para niños y adolescentes residentes de la Favela São Remo, vecina al campus universitario, a fin de comprender como la jerarquía social, que atraviesa la constitución de ambos grupos, interfiere en la producción de las memorias sobre la propia interacción ocurrida entre ellos. El análisis fue elaborado a partir del caso de la muerte de Daniel Pereira de Araújo, adolescente de 15 años, morador de la Favela San Remo, que desapareció cuando jugaba en el campus de la universidad, en noviembre de 1997.

PALABRAS CLAVE: Universidad de São Paulo. Favela. Memoria Histórica. Conflictos Sociales.

\section{NOTAS}

1) A primeira parte das fontes é composta por material bibliográfico e documental, a segunda é constituída por relatos obtidos a partir de entrevistas realizadas com moradores da São Remo que frequentaram o campus durante sua infância ou adolescência. A terceira é formada por um conjunto de notícias dos jornais Folha de São Paulo e 0 Estado de S. Paulo que fizeram a cobertura dos acontecimentos.

2) O termo "Comunidade USP" faz referência a um grupo de pessoas formado por estudantes, docentes e funcionários que possuem vínculo com a Universidade de São Paulo, o que lhes garante o direito de acessar alguns espaços e serviços que não são disponíveis ao restante da população. Vale ressaltar que a utilização desse termo se dá, apesar da significativa pluralidade de perfis e posicionamentos existente em meio a esse grupo.

3) A presença de moradores da São Remo trabalhando no campus realizando trabalhos de limpeza, jardinagem e outras ocupações socialmente desvalorizadas com baixa remuneração e condições precárias de contratação é relatada desde o final da década de 1970 por Blay e Martins (1980).

4) No início de 2017 foi construída uma nova guarita, blindada e, aos poucos, com a presença constante da polícia militar, os horários de fechamento dessa portaria foram estabelecidos conforme a regra das demais entradas de pedestre para o campus.

5) As interações entre as crianças e adolescentes da São Remo e a comunidade universitária podem ser compreendidas à luz das ideias de estigma, de Erving Goffman. Segundo Goffman (1982), ser estigmatizado significa desempenhar um papel estruturado, rotineiro e padronizado na sociedade. Ou seja, não há pessoas com estigmas, mas indivíduos que em determinadas situações destoam do que se estabelece hegemonicamente como normalidade. Essa condição não se manifesta necessariamente em todas as situações, o que muda com relação a cada estigma é a frequência com que se está na posição de destoante. Goffman (1982) sustenta que existem expectativas dos "normais" com relação à maneira como agem ou deveriam agir os estigmatizados. E assim, quando um deles supera ou foge a essas expectativas, há uma grande surpresa por parte dos primeiros. 0 
estigmatizado, por sua vez, ora não tem consciência de sua característica destoante, ora a utiliza como proteção.

6) Assinaram o relatório da Comissão os docentes: Prof. Dr. Fábio Konder Comparato, Profa. Dra. Ivette Senise Ferreira e Prof. Dr. Paulo Sérgio Pinheiro.

7) As entrevistas foram realizadas com o então prefeito da Cidade Universitária, Professor Antônio Rodrigues Martins, com um professor da Associação dos Docentes da USP (Adusp), um estudante membro do Diretório Central dos Estudantes da USP (DCE), um funcionário ligado ao Sindicato dos Trabalhadores da USP (SINTUSP) e o Delegado do $93^{\circ}$ Distrito Policial. Além disso, a comissão analisou os autos do Inquérito 344/97, do livro número 017, fls 51 v, de 3 de novembro de 1997.

8) Afirmação encontrada no artigo assinado pelo editorial da Folha de São Paulo - Há opção de lazer, diz USP. Folha de São Paulo. São Paulo, 8 nov. 1997.

9) Alguns autores interpretam-na como excludente devido à decisão de fechar seus portões ou apontam omissão no papel da instituição na promoção da cidadania. Neto (1997), por sua vez, afirmou que a morte de Daniel havia sido utilizada para fazer politicagem na eleição para a reitoria da Universidade e referia-se a dois dos autores de artigos anteriores nominalmente, desqualificando-os e às suas opiniões. Não explorarei aqui os detalhes dessa discussão, que teve resposta em Borin (1997a).

10) É possível notar ainda uma diferença entre as abordagens dos dois jornais examinados: o jornal O Estado de S. Paulo, começou a noticiar os fatos mais tarde e encerrou a cobertura mais cedo, no dia 27 de novembro, momento em que o laudo do IML ficou pronto. 0 jornal Folha de São Paulo noticiou o seu desaparecimento alguns dias antes (CABRAL, 1997c). Na Folha de São Paulo, após o encerramento oficial do caso, os debates com relação à universidade se estenderam. Além disso, é possível notar diferenças na maneira como os dois jornais abordaram os acontecimentos. Um exemplo que ilustra essa diferença é a referência feita às manifestações após a morte de Daniel, enquanto o jornal Folha de São Paulo utiliza frequentemente o termo "protesto", o jornal O Estado de S. Paulo utiliza o termo "vandalismo", referindo-se aos mesmos acontecimentos.

\section{REFERÊNCIAS}

ADORNO, Sérgio. Crianças e Adolescentes em Situação de Rua: o caso USP. Relatório Final. Núcleo de Estudos da Violência \& Instituto Ayrton Senna, USP, São Paulo, 1998.

ANTAR, Natalie. Corpo de jovem desaparecido é achado na USP. O Estado de S. Paulo, São Paulo, 6 nov. 1997. cad. Cidades.

ANTAR, Natalie. Amigos de garoto encontrado morto na USP reafirmam versão: quatro colegas de Daniel confirmaram em depoimento que seguranças os agrediram. $O$ Estado 
ROCHA, M. M.

de S. Paulo, São Paulo, 12 nov. 1997a. cad. Violência, p. C11.

BASTOS, Rosa. Para favelada, universidade é lugar de bacana: moradores de favela próxima criticam desprezo e preconceito no câmpus. O Estado de S. Paulo, São Paulo, 6 nov. 1997. Cad. Cidades, p. C9.

BARBOSA-PEREIRA, A. Os "rolezinhos" nos centros comerciais de São Paulo: juventude, medo e preconceito. Revista Latinoamericana de Ciencias Sociales, Niñez y Juventud, v. 14, n. 1, p. 545-557, 2016.

BARBOSA-FERREIRA. Compreender. In: BOURDIEU, Pierre (coord.). A miséria do mundo. 4a ed., Petrópolis: Vozes, 2001a, p. 693-732.

BORIN, J air. O segundo incêndio da USP. Folha de São Paulo, São Paulo, 10 nov. 1997. cad. Cotidiano.

BORIN, J air. A USP, o muro e a difamação. Folha de São Paulo, São Paulo, 5 dez. 1997a. cad. Opinião.

CABRAL, Otávio. Família reza pelo retorno de Daniel. Folha de São Paulo, São Paulo, 5 nov. 1997. cad. Cotidiano.

CABRAL, Otávio. PM assume a segurança no câmpus: Reitoria alega que guardas estavam sendo hostilizados; medida segue pelo menos até a segunda-feira. Folha de São Paulo, São Paulo, 8 nov. 1997a. cad. Cotidiano.

CABRAL, Otávio. Organizadores perderam controle de ato: entidades se disseram admiradas com a reação violenta de amigos do garoto encontrado morto na USP. Folha de São Paulo, São Paulo, 7 nov. 1997b. cad. Cotidiano.

CABRAL, Otávio. Fracassam buscas para encontrar garoto. Folha de São Paulo, São Paulo, 5 nov. 1997c. cad. Cotidiano.

CABRAL, Otávio. Dia de fúria 2: Revoltados com morte de garoto, funcionários, alunos e moradores da favela depredaram reitoria e ônibus. Folha de São Paulo, São Paulo, 7 nov. 1997d. cad. Cotidiano.

CABRAL, Otávio. Enterro de garoto reúne 300 pessoas. Folha de São Paulo, São Paulo, 7 nov. 1997e. cad. Cotidiano.

CABRAL, Otávio; OLIVEIRA, Marcelo. Família não crê em morte por afogamento. Folha de São Paulo, São Paulo, 6 nov. 1997. cad. Cotidiano. 
CARELLI, Gabriela. USP será aberta para visitas monitoradas: novo reitor diz no 10 dia no cargo que é preciso abrir câmpus para atividades culturais. O Estado de S. Paulo, São Paulo, 27 nov. 1997. cad. Cidades, p. C3.

CARELLI, Gabriela. Laudo do IML aponta morte por afogamento. O Estado de S. Paulo, São Paulo, 27 nov. 1997b. cad. Cidades.

CARTA da Associação Atlética Acadêmica Politécnica ao Diretor da Escola Politécnica da USP, São Paulo, 2000.

CARVALHO, M.; REZENDE, A. B. Formas de ser menino negro: articulações entre gênero, raça e educação escolar. In: CARVALHO, Marília Pinto de (Org.). Diferenças e desigualdades na escola. Campinas: Papirus, 2012.

COMISSÃO DE ACOMPANHAMENTO. Relatório da Comissão de Acompanhamento do Inquérito para apurar as circunstâncias e eventuais responsabilidades envolvendo a morte de Daniel Pereira de Araújo, instituída por Portaria/253197/GR, de 7 de novembro de 1997. Relatório do inquérito instaurado no $93^{\circ}$ Distrito Policial, São Paulo.

ENTIDADES da USP fazem manifesto. Folha de São Paulo, São Paulo, 5 nov. 1997. Reportagem Local. cad. Cotidiano.

FELINTO, Marilene. A universidade e a favela no verão paulista. Folha de São Paulo. São Paulo, 11 nov. 1997. cad. Cotidiano.

HÁ opção de lazer, diz USP. Folha de São Paulo. São Paulo, 8 nov. 1997. Reportagem Local. cad. Cotidiano.

KEHL, Marta Rita. A depredação da USP. Folha de São Paulo. São Paulo, 10 nov. 1997. cad. Opinião.

LEAL, Gláucia. A gente tá cansado de preconceito: garotos pedem justiça no caso de garoto morto e direito de ir ao câmpus sem serem molestados. O Estado de S. Paulo, São Paulo, 7 nov. 1997. cad. Cidades, p. C3.

LEAL, Gláucia. Alunos criticam câmpus fechado para a comunidade. $O$ Estado de $S$. Paulo, São Paulo, 8 nov. 1997a. cad. Violência, p. C9.

GOFFMAN, E. Estigma: notas sobre a manipulação da identidade deteriorada. Rio de Janeiro: Zahar, 1982. 
ROCHA, M. M.

MARCOVITCH, Jacques. Universidade Viva: Diário de um reitor. São Paulo: Mandarim, 2001.

MOTOYAMA, Shozo. USP 70 anos. imagens de uma história vivida. São Paulo: EDUSP, 2006.

NETO, Ricardo Bonalume. Morte e demagogia na USP. Folha de São Paulo, São Paulo, 28 nov. 1997. cad. Opinião.

OLIVEIRA, Marcelo. Crianças e adolescentes dizem que deverão se afastar da universidade depois da morte de Daniel: USP não é mais opção para favelados. Folha de São Paulo, São Paulo, 8 nov. 1997. cad. Cotidiano.

OFíCIO ao diretor da Faculdade de Ciências Farmacêuticas da USP, GR em 01 de abril de 1998, São Paulo.

PIVETTA, Marcos. Guardas não estão suspensos. Folha de São Paulo, São Paulo, 7 nov. 1997. cad. Cotidiano.

PIVETTA, Marcos; ROSSETI, Fernando. Para reitor, protesto foi manipulado. Folha de São Paulo, São Paulo, 7 nov. 1997. cad. Cotidiano.

PURVINNI, Larissa. Opiniões de alunos divergem. Folha de São Paulo, São Paulo, 8 nov. 1997. cad. Cotidiano.

POLLAK, Michael. Memória, Esquecimento, Silêncio. Estudos Históricos, Rio de Janeiro, v. 2, n. 3, p. 3-15, 1989.

PROGRAMA AVIZINHAR. Relatório de Atividades do Avizinhar. junho de 98/março de 2001. São Paulo, 1998-2001.

ROCHA, Mariana Machado. Quando a favela é Extensão da universidade: O Programa Avizinhar em meio às relações entre a USP e a São Remo. Dissertação (Mestrado). Universidade de São Paulo, São Paulo, 2016.

ROSSETI, Fernando. Para reitor, foi imprudência. Folha de São Paulo, São Paulo, 6 nov. 1997. cad. Cotidiano.

SCHIVARTCHE, Fábio. Amigo diz ter apanhado com galho de árvore na USP. Folha de São Paulo, São Paulo, 6 nov. 1997. cad. Cotidiano.

SHIRTS, Matthew. O câmpus é do povo. O estado de S. Paulo, São Paulo, 12 nov. 1997. cad. Crônica. 
WAISELFISZ, Julio J acobo. Mapa da violência 2013. Secretaria-Geral da Presidência da República: Brasília, 2013.

\author{
Mariana Machado Rocha: Doutoranda na Faculdade de Educação da USP e \\ Pesquisadora da Fundação Getúlio Vargas. \\ E-mail:machado.mari.r@smail.com
}

Este periódico utiliza a licença Creative Commons Attribution 3.0, para periódicos de acesso aberto (Open Archives Iniciative - OAI). 